\title{
Influences of Asphaltene Deposition on Formation Damage and Gas Coning
}

\author{
Masoud Riazi* and Khadijeh Zare \\ Enhanced Oil Recovery (EOR) Research Center, Shiraz University Shiraz, Iran
}

Received: April 03, 2018; Published: April 13, 2018

*Corresponding author: Masoud Riazi, Enhanced Oil Recovery (EOR) Research Center, School of Chemical and Petroleum Engineering, Shiraz University, Shiraz, Iran; Email: mriazi@shirazu.ac.ir

\begin{abstract}
Asphaltene deposition in porous media would lead to reduction of effective pore/throat radius when the pressure of reservoir fluid drops below the onset of Asphaltene flocculation pressure. Therefore, causing major problems such as formation damage, more pressure drop around the well-bore, increased tendency to water and gas coning and subsequently disruption the oil production rate and the economical oil recovery. The main objective of this study is to estimate the gas coning height in the vicinity of the production well- bore due to Asphaltene induced formation damage and investigate the effect of various flow rates on gas coning height using information of two reservoirs. The results prove Asphaltene damages the reservoir by reducing rock permeability and porosity and progressive increase of the skin factor and which can result in productivity impairment. So, it is important to clearly investigate formation damages because removing them is so expensive and sometimes impossible.
\end{abstract}

Keywords: Asphaltene Deposition; Asphaltene Precipitation; Formation Damage; Permeability Reduction; Water and Gas coning

\section{Introduction}

Asphaltene are components found in crude oil and defined as insoluble in n-alkanes and soluble in benzene and toluene [1]. According to their chemical structure, they are enriched in rings groups and they additional to carbon and hydrogen contain sulfur, oxygen, nitrogen atoms. Asphaltene is an undesirable and destructive product of petroleum production because of many problems related to its deposition. The tendency of Asphaltene to aggregate and precipitate onto surfaces depends on changing at reservoir conditions such as the oil composition, reservoir pressure and ambient temperature [2-4] and its deposition can cause obstructions in flow within the production systems, reducing of the hydrocarbon effective mobility ( / ) by

a) pore throat blockage

b) And absorbing on to the rock and altering wet ability of formation

c) increasing the reservoir fluid viscosity and also can have effect on the petro physical properties of porosity and permeability [5-8] during several processes mainly drilling ,coring, well completion, production , work over and injection of water or chemical for enhanced recovery [9-14].

Deposition of Asphaltene could happen anywhere in the production system, however the most damaging zone is in the vicinity of well-bore, and also the most dominant damage mechanism is blockage of effective pore bodies, in order to determine the degree of permeability reduction, prediction the onset of Asphaltene precipitation is necessary. Several authors have studied different models for Asphaltene deposition in core tests. Ali and Islam [15] injected crude oils with $3 \mathrm{wt} . \%$ of Asphaltene content into carbonate cores at four different rates $0.5,1,2$ and $3 /$ and calculated the permeability reduction by measuring the pressure drops across the core. Kamath et al. [8] investigated the effect of Asphaltene deposition on water flooding for both consolidated and unconsolidated sand packs. The cores which they used had porosity of 27.86 to $32.67 \%$ and permeability of 236 to $2380 \mathrm{md}$.

They presented that Asphaltene deposition has effect on reservoir rock permeability. Garrouch and Al-Ruhaimani [16] proposed a model to evaluate the variation of permeability due to Asphaltene deposition for homogenous and heterogeneous formations. Civan et al. [17] derived the equation of reduced permeability as a function of porosity and after that Liu and Civan [18] and Chang and Civan [19] modified the reduced permeability as a function of porosity by using the permeability modification coefficient. In this work, the impact of Asphaltene precipitation on pressure drop and initial permeability around a well-bore is investigated. As shown in Figure 1, it is attempted to find a relationship between the Asphaltene precipitation and the gas 
coning under different flow rates. Yet, due to lack of knowledge about the Asphaltene properties and their complex chemical structures we are unable to achieve a clear picture of the nature of Asphaltene. Therefore, developing analytical and experimental methods for further understanding, preventing and monitoring formation damage in oil reservoirs is necessary.

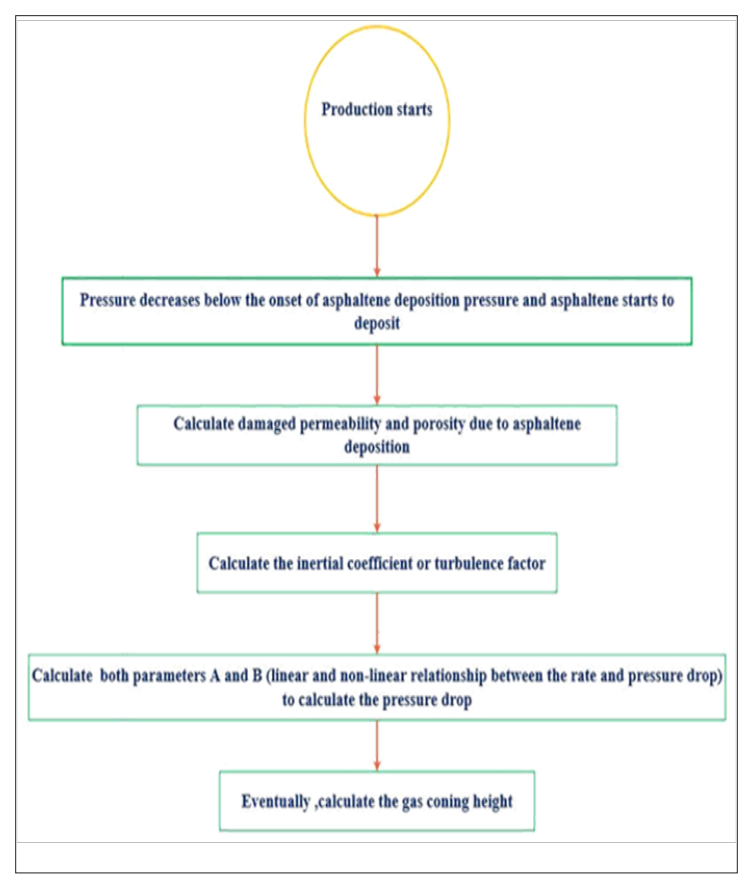

Figure 1: Procedure of numerical solution for the mathematical model.

\section{Asphaltene Deposition Theory and Problems Statement}

Problems rising during the oil production could dramatically increase the production costs. Among these, Asphaltene deposition in reservoirs and the production facilities is the predominant problem. Typically, at initial reservoir condition Asphaltene exist in crude oils are stabilized by associated resin molecules $[20,21]$ but during production of a well where the pressure starts simultaneously declining below the onset of Asphaltene aggregation at which Asphaltene starts to precipitate. Referring to Figure 2, the destabilized Asphaltene cause plugging of the formation and production surface facilities thus reducing the rock permeability and porosity and diffusivity reduction in this damaged region. A schematic of the deterioration of pressure at different production times ( $t 5>t 4>t 3>t 2>t 1)$ in the vicinity of well-bore afflicted by Asphaltene deposition is shown in Figure 3. When the pressure falls near the wellbore, it may result in Asphaltene precipitation then increases in skin and, consequently greater pressure drop; this would result in the reduction of oil flow rates. Therefore to make further advancements in understanding Asphaltene impairment as a cause of pressure decline Darcy's equation is used to calculate damaged pressure drop:

$$
\begin{gathered}
\mathrm{P}-\mathrm{P}_{\mathrm{w}}(\text { no skin })=\frac{\mu_{0} \mathrm{Q} \mathrm{B}}{2 \pi K_{i n} h}\left(\ln \frac{r_{s}}{r_{w}}\right) \\
\mathrm{P}-\mathrm{P}_{\mathrm{w}}(\text { with skin })=\frac{\mu_{0} \mathrm{Q} \mathrm{B}{ }_{0}}{2 \pi K_{s} h}\left(\ln \frac{r_{s}}{r_{w}}\right) \\
\Delta \mathrm{P}_{\text {damage }}=p_{w}(\text { with skin })-p_{w}(\text { no skin })
\end{gathered}
$$

$$
\Delta \mathrm{P}_{\text {damage }}=\frac{\mu_{0} \mathrm{Q} \mathrm{B}_{0}}{2 \pi K_{\text {in }} h}\left(\frac{K_{\text {in }}}{K_{s}}-1\right)\left(\ln \frac{r_{s}}{r_{w}}\right)
$$

The skin factor, which reduces the capacity of the production, is defined as additional resistance to flow and it is denoted by the symbol $\mathrm{S}$ and defined as follows:

$$
\mathrm{S}=\left(\frac{K_{i n}}{K_{s}}-1\right)\left(\ln \frac{r_{s}}{r_{w}}\right)=\frac{2 \Pi K_{i n} h}{\mu_{0} \mathrm{QB}_{0}} \square \mathrm{P}_{\text {damage }}
$$

Once the additional pressure drop due to skin is calculated by Eq. (4) and the skin factor can be estimated by Eq. (5). The positive skin indicates that the effective permeability around well-bore has been reduced. Outer radius of the altered zone and $\mathrm{B}_{\mathrm{o}}$ is oil formation volume factor.

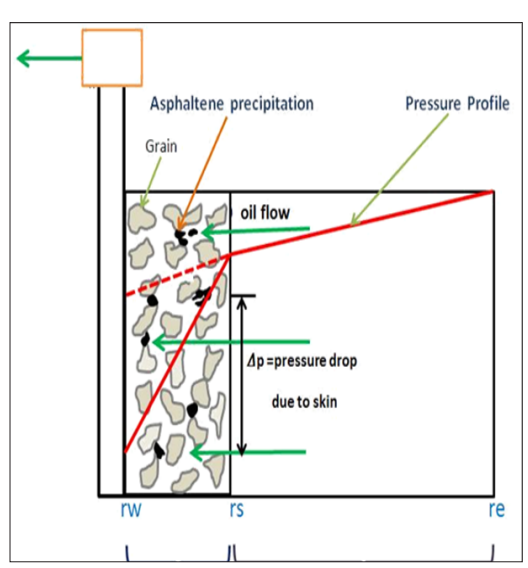

Figure 2: Well production with asphaltene deposition. 


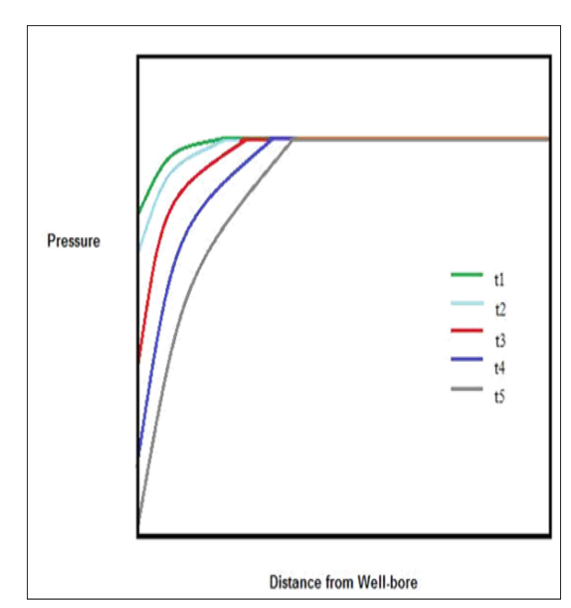

Figure 3: Reservoir rock pressure profile at different production times.

\section{Coning Phenomenon}

The concept of gas coning has been one of the major concerns of reservoir engineers as it significantly reduces oil production, increases the cost of production operations, reduces the efficiency of the depletion mechanism and leads to early well shut down. Generally, there is a balance between the gravitational forces, due to fluid density differences, and the viscous forces, related to the pressure drawdown which causes fluids to flow in the reservoir at any point on and away from the completion interval. When the viscous forces exceed that of the gravitational forces the gas cone forms around. Thus gas is produced along with the oil as shown in Figure 4 . When the gas reaches the production well, the pressure drawdown near the well-bore causes the gas which is the more mobile phase to produce faster than oil, thereby gas flow becomes more dominant than the oil flow. As mentioned previously, skin accelerates the gas coning because there is a direct link between the production rate of a well and both the pressure drawdown and the reservoir permeability. As a result, gas coning is easier to occur in a low permeability reservoirs. Pressure losses at different flow regimes may be described by various equations, basically known as Darcy flow equation, Pre-Darcy flow equation and Non-Darcy or turbulent flow equation.

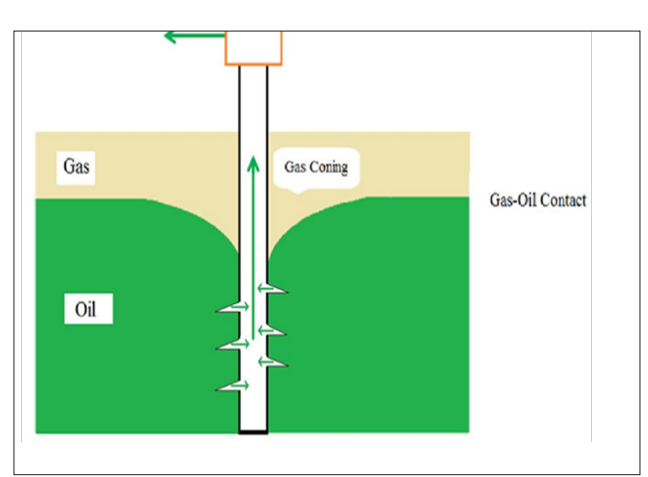

Figure 4: Cross-section view of gas coning in a vertical well.

The simplest model of pressure drop for incompressible Newtonian liquid is obtained from Darcy's law as shown below:

$$
\Delta \mathrm{P}=\mathrm{AQ}
$$

Where $\mathrm{Q}$ is reservoir flow rate and parameter A expresses the linear proportionality between the rate and pressure drop, which itself is governed by:

$$
\mathrm{A}=\frac{1}{\mathrm{PI}}=\frac{\mu_{0} \mathrm{~B}_{0}}{2 \pi K_{i n} h}\left(\ln \frac{r_{e}}{r_{w}}+\sum S\right)=\frac{\mu_{0} \mathrm{~B}_{0}}{2 \pi K_{s} h}\left(\ln \frac{r_{e}}{r_{w}}\right)=\frac{\mu_{0} \mathrm{~B}_{0}}{2 \pi K_{i n} h}\left(\ln \frac{r_{s}}{r_{w}}\right)
$$

Where PI is the well productivity index, re is well-bore drainage radius, $\mathrm{S}$ is skin factor. However, near the well-bore when the velocity is high especially with gas production, the turbulent flow may occur and Darcy's law is replaced by a non-linear Forchheimer's equation which is described as:

$$
\Delta \mathrm{P}=\mathrm{AQ}+\mathrm{BQ}^{2}
$$

Parameter B represents the non- linear relationship between the rate and pressure drop and is calculated as follows:

$$
\mathrm{B}=\frac{\beta \rho_{0} \mathrm{~B}_{0}}{4 \pi^{2} h^{2}}\left(\frac{1}{r_{w}}-\frac{1}{r_{e}}\right)
$$

Where $\rho_{0}$ the oil density and $\beta$ is the flow resistance, often called the velocity coefficient or turbulence factor, Firozabad and Katz [22] found that the inertial coefficient $\beta$ decreased with increasing permeability and porosity accordingly to the following expression:

$$
\beta=\frac{7.21 * 10^{7}}{(K * \phi)^{1.85}}
$$

Where $\varnothing$ and $\mathrm{K}$ represent the porosity and permeability of formation, respectively. Both A and B are constants that depend on flow geometry and the physical properties of rock and fluids. Birks [23] later defined gas coning heights for high flow rates at which the pressure drop around the well-bore increases dramatically and a turbulence pressure drop is developed as:

$$
h_{g}=\frac{\Delta P}{2.3\left(G_{0-} G_{g}\right) \log \left(\frac{r_{e}}{r_{w}}\right)}=\frac{\mathrm{AQ}+\mathrm{BQ}^{2}}{2.3\left(G_{0-} G_{g}\right) \log \left(\frac{r_{e}}{r_{w}}\right)}
$$

$\mathrm{G}_{\mathrm{o}}$ and $\mathrm{G}_{\mathrm{g}}$ are the respective oil and gas gradients, respectively.

\section{Results and Discussion}

We have previously proved that the gas coning height thus the decline in production rate is linked to formation damage due to Asphaltene deposition. The mathematical model was carried out to estimate the gas coning height was based on a couple of publications developed by Leontarakis [24] and Wang and Civan [25].

\section{Effect of Pressure Drop}

Assuming that the flow rate is kept constant and the bottom hole flowing pressure decreases below the Asphaltene onset pressure, but reservoir pressure is more than the onset of Asphaltene pressure. By using the Eq. (8) the pressure drop is calculated then the amount of the gas coning height can be obtained from Eq. (11) by using Eq. (8) that is evident in Figure 5. The profiles are evaluated for production time 48, 96, 192, 348 and 1000 hours at constant production rate. The results show that at the wellbore the gas coning height is significantly increases because the formation damage caused by Asphaltene deposition over time is severe near the well-bore but in the region $r>18 \mathrm{ft}$ as long as the flow rate remains constant porosity, permeability, and pressure profiles remain unchanged with time then gas-oil contact (GOC) advancement is kept constant. 


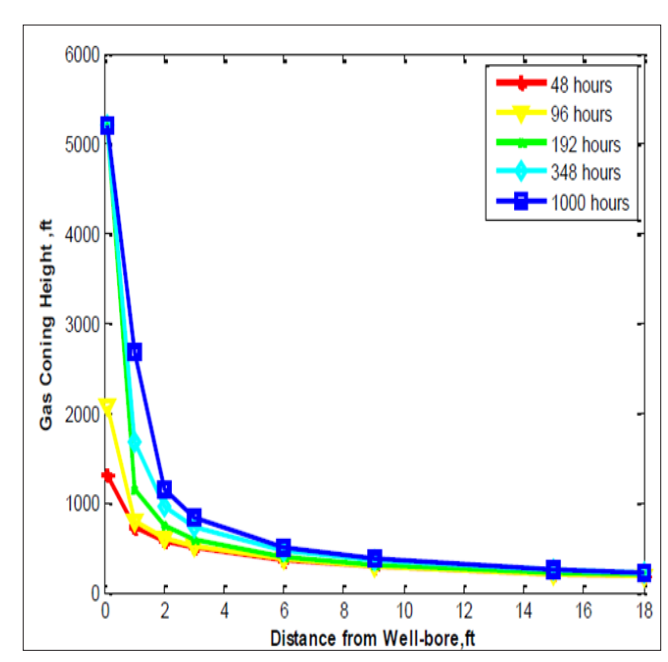

Figure 5: Gas coning height profile at different production times

\section{Effect Of Production Rate Decline}

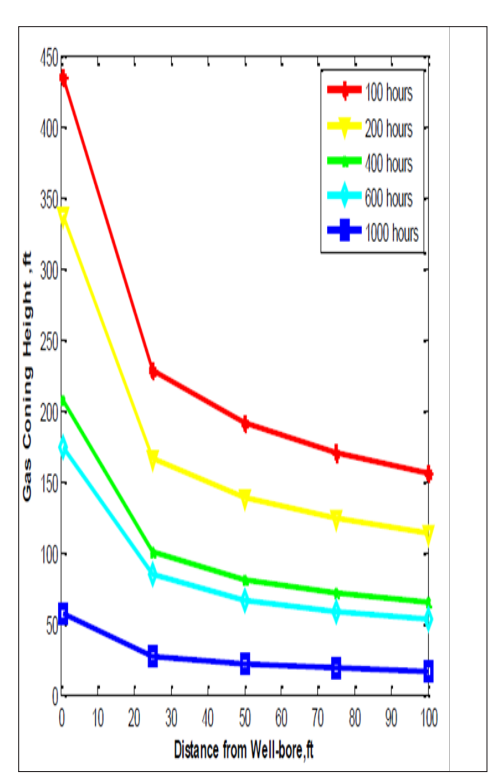

Figure 6: Gas coning height profile at different production times.

In this paper is assumed that the production rate declines rapidly from about 4000 to $100 \mathrm{Bbl}$ /day because of Asphaltene deposition. The gas coning height as function of movable gas-oil contact is illustrated in Figure 6 with the Eq. (11) for production times 100, 200, 400, 600and 1000 days to study the effect of different flow rate on gas coning. as mention before, when pressure in the whole reservoir decreases then GOC advances due to the compressibility of gas reservoir but more Asphaltene deposition leads to the additional pressure drop and eventually increased tendency to gas coning in the near well-bore region unless as seen in the Figure 6 the production rate of the well is decreased to extravagantly low values, then gas coning height will reduce but this is not favor of reservoir engineers.

\section{Conclusion}

According to this analysis the following conclusions can be drawn:

Formation damage is not completely understood or predictable and it is not necessarily reversible. Therefore, it is better to prevent and or control damage than restore the rock permeability. Formation damage due to Asphaltene can occur during primary, secondary and tertiary production and lead to reduce available pore diameter for oil flow, increases Pressure drop around the wellbore, excesses coning phenomena, decreases well performance and consequently leads to early shut down of the wells. Results from the evaluation indicate that formation damage takes place at the wellbore and deep part of the reservoir is not affected and also there is a higher chance that gas coning takes place in the vicinity of the well-bore than that in the rest of the reservoir. Gas coning depends sharply on flow rate; hence any change in flow rate affects the gas coning height. Therefore, Analysis of the data from the high rate and subsequent low rate production periods indicated that with the decreasing in the production rate, the gas coning height is significantly reduced but for economic reasons, the desired production rate is often greater than the critical rate.

\section{Nomenclature}

a) PI Well productivity index, $\mathrm{cm} 3 / \mathrm{sec} / \mathrm{atm}$

b) Linear proportionality between the rate and pressure drop, atm $/ \mathrm{cm}^{3} / \mathrm{sec}$

c) Non-linear relationship between the rate and pressure drop, atm / $\left(\mathrm{cm}^{3} / \mathrm{sec}\right)^{2}$

d) Q Flow rate, $\mathrm{cm}^{3} / \mathrm{sec}$

e) P Pressure, atm

f) Pw Bottom-hole pressure, atm

g) $\quad \mu$ Viscosity, cp

h) K Permeability, md

i) $\quad \mathrm{K}_{\mathrm{in}}$ Initial permeability, md

j) $\quad \mathrm{k}_{\mathrm{s}}$ Damaged permeability, md

k) h Net thickness of the formation, $\mathrm{cm}$

l) $\mathrm{h}_{\mathrm{g}}$ Gas coning height, $\mathrm{cm}$

m) $r_{w}$ Well-bore radius, $\mathrm{cm}$

n) $r_{s}$ Outer radius of the altered zone, $\mathrm{cm}$

o) $r_{\mathrm{e}}$ Well-bore drainage radius, $\mathrm{cm}$

p) S Skin factor

q) $B_{0}$ Oil formation volume factor

r) $\rho_{\mathrm{o}}$ Oil density, g / cm3

s) $\varnothing$ Porosity of the formation, fraction 
t) $\beta$ Flow resistance, $1 / \mathrm{cm}$

u) $\mathrm{G}_{0}$ Oil gradient, atm $/ \mathrm{cm}$

v) $\mathrm{G}_{\mathrm{g}}$ Gas gradient, atm/cm

\section{Subscripts}

$$
\mathrm{o}=\mathrm{oil} \mathrm{g}=\mathrm{gas}
$$

\section{References}

1. Sheu EY, Storm DA (1995) Colloidal Properties of Asphaltene in Organic Solvents. Sheu EY and Mullins OC (Eds.). Asphaltenes Fundamentals and Applications p. 1-52.

2. Ali LH, Al-Ghannam KA (1981) Investigations into Asphaltene in Heavy Crude Oil: Effect of Temperature on Precipitation by Alkane Solvents, the Science and Technology of Fuel and Energy 60(11): 1043-1046.

3. Angle CW, Long Y (2006) Precipitation of Asphaltenes from SolventDiluted Heavy Oil and Thermodynamic Properties of Solvent-Diluted Heavy Oil Solutions. The Science and Technology of Fuel and Energy 85 (4): 492-506.

4. Hirschberg A, deJong, LNJ (1984) Influence of Temperature and Pressure on Asphaltene Flocculation. SPE Society of Petroleum Engineers Journal 24(3): 283-293.

5. Buckley JS, Liu Y, Xina Xie, Morrow NR (1997) Asphaltenes and Crude Oil Wetting: the Effect of Oil Composition. SPE Journal 2(2): 107-119.

6. Crocker ME, Marchin LM (1988) Wettability and Adsorption Characteristics of Crude Oil Asphaltene and Polar Fractions. SPE Journal of petroleum technology 40(4): 470-474.

7. Kamath VA, Yang J, Sharma GD (1993) Effect of Asphaltene Deposition on Dynamic Displacements of Oil by Water. Paper SPE26046 presented at SPE Western Regional Meeting, Anchorage Alaska 26-28: 179.

8. Piro G, Canonico LB, Galbariggi G, Bertero L (1996) Asphaltene Adsorption onto Formation Rock: An Approach to Asphaltene Formation Damage Prevention. SPE Production \& Facilities 11(3): 156-160.

9. Burke NE, Hobbs RE, Samir Kashou F (1990) Measurement and Modelling of Asphaltene Precipitation. SPE Journal of petroleum technology 42(11): 1440-1446.

10. Islam MR (1995) Potential of Ultrasonic Generators for Use in Oil Wells and Heavy Crude Oil Bitumen Transportation Facilities. Sheu EY and Mullins OC (Eds.). Asphaltenes Fundamentals and Applications pp. 191218.

11. Kokal SL, Najman J (1992) Measurement and Correlation of Asphaltene Precipitation from Heavy Oils by Gas Injection. Journal of Canadian petroleum technology 31(4): 1-8.
12. Leontaritis KJ, Mansoori GA (1988) Asphaltene Deposition: a Survey of Field Experiences and Research Approaches. Journal of Petroleum Science and Engineering 1(3): 229-239.

13. Minssieux L (1997) Core Damage from Crude Asphaltene Deposition. Paper SPE 37250 presented at International Symposium on Oilfield Chemistry Houston Texas 18-21 February pp. 1-19.

14. Novosad Z, Costain TG (1990) Experimental and Modelling Studies of Asphaltene Equilibria for a Reservoir under CO2 Injection. Paper SPE 20530 presented at SPE Annual Technical Conference and Exhibition New Orleans Louisiana 23-26 September pp. 1-9.

15. Ali MA, Islam MR (1998) The Effect of Asphaltene precipitation on Carbonate Rock Permeability: An Experimental and Numerical Approach. SPE Production \& Facilities 13(3): 178-183.

16. Garrouch AA, Al-Ruhaimani FA (2005) Modelling Permeability Reduction Caused by Asphaltene Deposition. Paper SPE 96697 presented at SPE Annual Technical Conference and Exhibition Dallas Texas 9-12 October.

17. Civan F, Knapp RM, Henry Ohen A (1989) Alteration of Permeability by Fine Particle Processes. Journal of Petroleum Science and Engineering 3(1-2): 65-79.

18. Liu X, Civan F (1996) Formation Damage and Filter Cake Buildup in Laboratory Core Tests: Modeling and Model-Assisted Analysis SPE Formation Evaluation 11(1): 26-30.

19. Chang, FF, Civan F (1997) Practical Model for Chemically Induced Formation Damage. Journal of Petroleum Science and Engineering 17(12): 123-137.

20. Kawanaka S, Leontaritis KJ, Park SJ, Mansoori GA (1989) Thermodynamic and Colloidal Models of Asphaltene Flocculation. American Chemical Society Symposium Series 396: 443-458.

21. Leontaritis KJ, Mansoori GA (1987) Asphaltene Flocculation during Oil Production and Processing: a Thermodynamic-Colloidal Model. Paper SPE 16258 presented at SPE International Symposium on Oilfield Chemistry San Antonio Texas 4-6 February pp. 1-10.

22. Firoozabadi A, Katz DL (1979) an Analysis of High Velocity Gas Flow Through Porous Media. SPE Journal of petroleum technology 31 (2): 211-216.

23. Birks J (1963) Coning Theory and Its Use in Predicting Allowable Producing Rates of Wells in a Fissured Limestone Reservoir. Iranian Petroleum Institute Bull (12,13): 470.

24. Leontaritis KJ (2005) Asphaltene Near-Well-bore Formation Damage Modeling. Journal of Energy Resources Technology 127(3): 191-200.

25. Wang S, Civan F (2005) Modeling Formation Damage by Asphaltene Deposition during Primary Oil Recovery. Journal of Energy Resources Technology 127(4): 310-317.

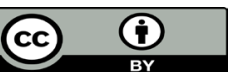

This work is licensed under Creative Commons Attribution 4.0 License

Submission Link: https://biomedres.us/submit-manuscript.php

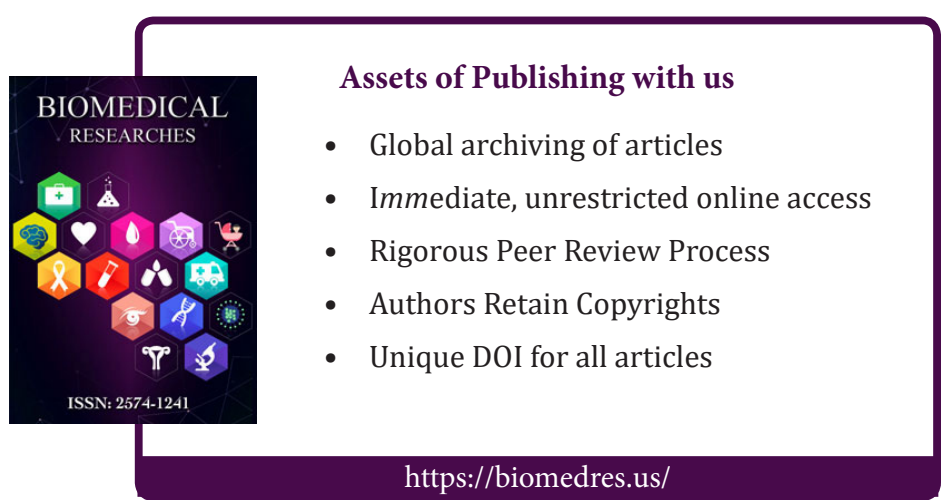

